\title{
The migration and fusion events related to ROCK activity strongly influence the morphology of chicken embryo intestinal organoids
}

\author{
Małgorzata Pierzchalska ${ }^{1}$ (D) $\cdot$ Małgorzata Panek $^{1} \cdot$ Maja Grabacka $^{1}$
}

Received: 11 May 2018 / Accepted: 20 September 2018 / Published online: 16 October 2018

(C) The Author(s) 2018

\begin{abstract}
The method of organoid culture has become a tool widely used in gastrointestinal research, but so far, the migration of organoids derived from gut epithelium and formed in 3D Matrigel matrix has not been reported and studied. The intestinal epithelial tissue derived from 19-day-old chicken embryo was cultured in Matrigel and the dynamic properties of the forming organoids were analyzed by time-lapse image analysis. It was observed that about one in ten organoids actively moved through the matrix, at a speed of $10-20 \mu \mathrm{m} / \mathrm{h}$. Moreover, rotation was observed in the majority of organoids that did not migrate long distances. The fusion events took place between organoids, which collided during the movement or growth. In our previous paper, we showed that the presence of Toll-like receptor 4 ligand, Escherichia coli lipopolysaccharide (LPS, $1 \mu \mathrm{g} / \mathrm{ml}$ ), increased the mean organoid diameter. Here, we confirm this result and demonstrate that the Rho-associated protein kinase (ROCK) inhibitor Y-27632 $(10 \mu \mathrm{M})$ did not completely abolish organoid migration, but prevented the fusion events, in both LPS-treated and untreated cultures. In consequence, in the presence of Y-27632, the differences between cultures incubated with and without LPS were not visible. We conclude that migration and fusion of organoids may influence their morphology and suggest that these phenomena should be taken into account during the design of experimental settings.
\end{abstract}

Keywords Intestinal organoids · Collective cell movement · Organoid fusion and rotation $\cdot$ Rho-associated protein kinase $\cdot$ Lipopolysaccharide $\cdot$ Chicken

\section{Introduction}

The collective cell migration is of profound importance for development, tissue morphogenesis, regeneration, and cancer progression in multicellular organisms, but its mechanism is not fully understood, because this phenomenon is difficult both to observe in vivo and to analyze in vitro (Scarpa and Mayor 2016). The normal epithelial tissue used to be considered as

Handling Editor: Margit Pavelka

Electronic supplementary material The online version of this article (https://doi.org/10.1007/s00709-018-1312-3) contains supplementary material, which is available to authorized users.

Małgorzata Pierzchalska

malgorzata.pierzchalska@urk.edu.pl

1 Department of Food Biotechnology, Faculty of Food Technology, The University of Agriculture in Kraków, Balicka 122, 30-149 Kraków, Poland relatively static. Recently, however, it has been suggested that epithelial sheets may transit from a jammed (more static) to an unjammed (more fluidic) state (Pegoraro et al. 2016). It was also previously reported that epithelial spheroids of vertebrates formed in 3D conditions (Rørth 2012) and Drosophila organlike structures called egg chambers rotate in an actin and myosin-dependent manner (Viktorinová et al. 2017) therefore exhibiting a sort of collective cell migration.

In the last few years, a diversity of organoid cultures has been successfully developed, leading to numerous publications based on the technique (Simian and Bissell 2017). The methods of spheroid and organoid cultures turned out to be particularly important for gastrointestinal studies. Since the pioneering papers, published almost 10 years ago, describing the mouse enteroids derived from intestinal crypts or stem cells embedded in the Matrigel layer (Sato et al. 2009; Ootani et al. 2009), various gastrointestinal organoids have become a popular tool in research into gut physiology. Although these new methods certainly hold great promise, they also raise some important concerns. The standardization and interpretation of results in organoid research could be 
difficult due to structural and histological complexity, as well as dynamic changes in morphology during the time of culture (Zachos et al. 2016).

Many papers published recently have analyzed changes in the number, size, and shape of the intestinal organoids cultured under various conditions. The results are usually interpreted in the context of the balance between stem cell proliferation and differentiation. In such papers, the area or diameter and the number of organoids per well (i.e., seeding efficiency) are commonly calculated parameters (Beyaz et al. 2016, Matsumoto et al. 2016). We have recently established the method of culture of chicken intestinal organoids comprising both epithelial and mesenchymal cells (Pierzchalska et al. 2012) and demonstrated that their growth is boosted by the presence of some Toll-like receptor (TLR) ligands or probiotic bacteria in the culture milieu. Organoids cultured in the presence of live Lactobacillus acidophilus LA5, LPS from Escherichia coli O111:B4 (TLR4 agonist) or Pam3CysSerLys4 (TLR2 agonist) were significantly larger compared with organoids cultured in standard conditions (Pierzchalska et al. 2017).

Here, we focus on image analysis revealing the remarkable dynamic and migratory properties of chicken intestinal organoids and suggest that the generally overlooked collective cell movement and fusion events may profoundly affect the morphology of the organoids.

\section{Materials and methods}

\section{Organoid culture}

The embryonated eggs from Ross 308 hens were obtained from a local professional hatchery (Krak-Drób, Sciejowice, Poland). Embryonic chicken intestinal epithelium fragments were isolated from small intestines removed from decapitated 19-day-old embryos, as previously described (Pierzchalska et al. 2016). The medium composition was as follows: DMEM/F12 (PAA Laboratories GmbH, Pasching, Austria) with antibiotic-antimycotic solution (Zell Shield; Minerva Biolabs, Berlin, Germany), insulin-transferrin-selenium premix (BD Biosciensces, San Diego, CA, USA), and epidermal growth factor (EGF, $25 \mathrm{ng} / \mathrm{mL})$, R-spondin 1 (500 ng/ml), Noggin (25 ng/ml), and WNT3a (10 ng/ml) (all R\&D Systems, Minneapolis MN, USA) with $5 \mu \mathrm{g} / \mathrm{mL} \mathrm{PGE}_{2}$ (Cayman Chemical, Ann Arbor, MI, USA) and chicken serum ( $0.25 \%$, PAN Biotech, Aidenbach, Germany). The cell culture inserts located in the compatible 12-well culture plates (0.4- $\mu \mathrm{m}$ pore size, transparent; BD Biosciences) were coated with $200 \mu \mathrm{l}$ Matrigel $^{\mathrm{TM}}$ (Matrigel Basement Membrane Matrix, Corning, USA) tissue suspension 1 to 1 mixture. In some experiments, ultrapure LPS from Escherichia coli O111:B4 (1 $\mu \mathrm{g} / \mathrm{ml}$, InvivoGen, France) or Rho protein kinase inhibitor, Y-27632 (10 $\mu \mathrm{M}$, Seleckchem, Munich, Germany) were added to the medium at the point of establishing the organoid culture. The medium $(750 \mu \mathrm{l})$ was transferred to the lower chamber and, after jellification of the Matrigel layer, to the upper chamber $(250 \mu \mathrm{l})$ of insert-containing wells.

\section{Time-lapse microscopic image analysis and calculation of parameters defining organoid culture appearance}

The cultures were observed with an inverted Axio Observer Z1 microscope equipped with a thermostatic incubation chamber with $\mathrm{CO}_{2}$ influx (Zeiss, Munich, Germany). For timelapse recording, the images from at least five fields of view from each culture were captured with an AxioCam HR digital camera. The recording was controlled by Zen 2012 software and images were collected at 30-min intervals using a $\times 5$ or $\times$ 10 objective. The recording started about $1 \mathrm{~h}$ after the establishment of the culture and lasted for 48-72 h. The organoid projection borders were contoured manually using the Zen 2012 graphical tools, in each field of view (at least 50 organoids from one culture) and the mean areas of organoid projection were calculated, as well as the mean number of organoids in one field of view (the mean $\pm \mathrm{SD}$ of at least five measurements are presented on graphs). The fusion events were counted in the first 2 days of culture by the analysis of time-lapse films (five films per experimental point). Statistical analysis was performed using Statistica 9 software. An ANOVA test confirmed the statistical significance of the differences in parameter characteristic of the cultures kept in the presence or absence of Y27632 (the $p$ value below 0.05 was considered significant).

\section{Total cellular protein isolation and immunoblotting}

The Matrigel matrix containing organoids was detached from insert membranes, washed twice with cold PBS, and incubated in Matrisperse (BD Biosciences) on ice for $30 \mathrm{~min}$. The released organoids and cells were centrifuged $(1000 \times g$ for $5 \mathrm{~min}$.) and the pellets were lysed with RIPA buffer (Thermo Fisher Scientific) Then, $20 \mu \mathrm{g}$ of total cellular protein were subjected to PAGE in $8 \%$ polyacrylamide gels and transferred to the nitrocellulose membrane. Protein extracts were also prepared with a RIPA buffer from tissue fragments of chicken intestinal epithelium after centrifugation of the suspension $\left(1000 \times g, 4{ }^{\circ} \mathrm{C}\right)$. The chicken embryonic intestines were incubated in chelating agent as with the establishment of the culture. The immunodetection was undertaken as previously described (Panek et al. 2018) using the following antibodies: polyclonal anti-sucrase-isomaltase (1:200, SAB2102141, Sigma-Aldrich, St. Louis, MO, USA), monoclonal anti- $\alpha$ smooth muscle actin $(1: 1000,1 \mathrm{~A} 4$, Sigma-Aldrich, St. Louis, MO, USA), monoclonal antibody against chicken villin (1:2000, MCA292, AbD Serotec, Raleigh, NC, USA). 
Immunodetection of reference protein was performed on the same membrane without stripping, using the anti-growth factor receptor-bound protein 2 mouse monoclonal antibody (BD Transduction laboratories) diluted 1:3000. The signal was visualized using SignalFire ${ }^{\mathrm{TM}}$ ECL Plus Reagent (Cell Signaling Technology Inc., USA) and X-ray films.

\section{Results}

The epithelial fragments isolated by the chelation of calcium ions vary in shape and size. The analysis of total proteins derived from initial intestinal tissue preparation by immunoblotting revealed the presence of villin (which is a protein marker of both mature enterocytes and their progenitors), sucrase-isomaltase (a differentiated enterocytes marker), and a very small amount of $\alpha$-sma (a marker of myofibroblasts) (Fig. 1d). In approximately $1 \mathrm{~h}$, simultaneously with the jellification of the surrounding Matrigel, some fragments of epithelium closed up, forming structures which were more compact and had a diameter of between 10 and $40 \mu \mathrm{m}$. Observation of the growth of organoids in the first $24 \mathrm{~h}$ revealed that the majority of those fragments enlarged rapidly, reaching about $200 \mu \mathrm{m}$ in diameter, and simultaneously transformed into hollow spheres covered with epithelial cells accompanied by a few myofibroblasts (organoids with empty lumens are formed between 4 and $10 \mathrm{~h}$ ). Time-lapse recording indicated that a substantial number of tissue fragments not only grew into organoids but also moved inside the Matrigel matrix. The migratory activity observed in about $10 \%$ of organoids started as early as the first $2 \mathrm{~h}$ of culture and was independent of lumen formation. The moving organoids reshaped much more rapidly and frequently had an elongated morphology. Typically, the more static an organoid, the more spherical was its morphology (Fig. 1a, Suppl. video 1). The distances covered by organoids in $24 \mathrm{~h}$ varied greatly (mean value 292, range 144-458 $\mu \mathrm{m}$ ). In consequence of the growth and movement, the separate tissue fragments bumped into each other in Matrigel and eventually fused. The frequency of fusion events was high and the majority of organoids on the second day of culture were engaged in at least one fusion event (Fig. 1b, Suppl. videos 1 and 2). Over time, fusion events and migration became occasional whereas the rotation remained the most frequently observed type of movement. Nevertheless, some organoids with empty lumen in the 2day-old cultures could still move and fuse (Suppl figure. 1, Suppl. video 3).

We previously showed that the addition of lipopolysaccharide (LPS) can influence the growth of organoids during the first 3 days of culture in Matrigel, by triggering the formation of larger structures with more irregular shapes as compared to organoids not treated with this TLR4 agonist (Pierzchalska et al. 2017). Here, we used a ROCK inhibitor (Y-27632,
$10 \mu \mathrm{M})$, both alone and simultaneously with LPS, to check whether the inhibitor was able to reverse the LPS action. We observed the increase in spheroid numbers and the decrease in their size, both in LPS-treated and untreated cultures. The reason for this could be the lower rate of organoid fusion in inhibitor-treated culture (Fig. 1e). The analysis of total cellular protein isolated from 4-day-old cultures indicates that stimulation with LPS resulted in a slightly increased expression of a marker of differentiated enterocytes and sucrase-isomaltase. Treatment with Y27632 inhibitor did not abolish this effect. On the contrary, even ROCK inhibition by Y-27632 alone caused an increase in the marker expression of enterocytes. Moreover, the stimulation of mesenchymal cell growth by ROCK inhibition is suggested by the fact that a myofibroblast marker, $\alpha$-SMA, is more abundant in the samples from inhibitor-treated cultures (Fig. 1d). The presence of numerous small organoids strongly attached to each other was the most striking morphological feature of cultures treated with Y-27632 (Fig. 1c). The analysis of organoid behavior on time-lapse recorded films indicates that although the inhibitor is not able to abolish migration of spheroids, it acts powerfully in preventing the fusion events (Fig. 1e, Suppl. video 4).

\section{Discussion}

The time-lapse video recording of the chicken embryo intestinal organoid cultures in Matrigel clearly demonstrates that intestinal organoids cannot only fuse, as others incidentally reported in mammalian systems (Jabaji et al. 2014, Sachs et al. 2017), but also simultaneously show migratory activity-rotation and directional movement. Such observation prompts immediate questions as to why the phenomenon was mostly overlooked by others and what is the mechanism responsible for such dynamic events.

Despite some excellent recent studies on the cohesive movement of various epithelial cell clusters through dense 3D extracellular matrix (Sharma et al. 2015, Sato et al. 2015, Hiraiwa et al. 2017), the understanding of this process remains elusive. It is generally supposed that such movement must engage the mechanical forces related to the surrounding matrix remodeling (Gjorevski et al. 2015). In this connection, it is important to emphasize that the methodology we used for culture establishment is slightly different to that generally applied for mammalian organoids. We prepared the mixture of Matrigel and intestinal tissue fragments in a suspension in which the final concentration of Matrigel reached 50\%. A drop $(200 \mu \mathrm{l})$ of this mixture was distributed onto the surface of porous membranes of cell culture inserts. We found this procedure to be an effective way of supporting the growth of the organoids, as compared to the method in which the cells are embedded in more concentrated Matrigel directly covering the cell culture dish. It emerged that organoid movement was 
a
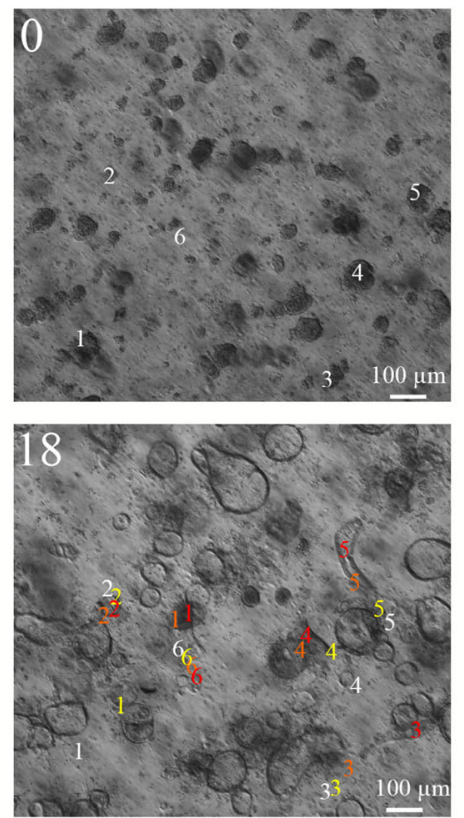
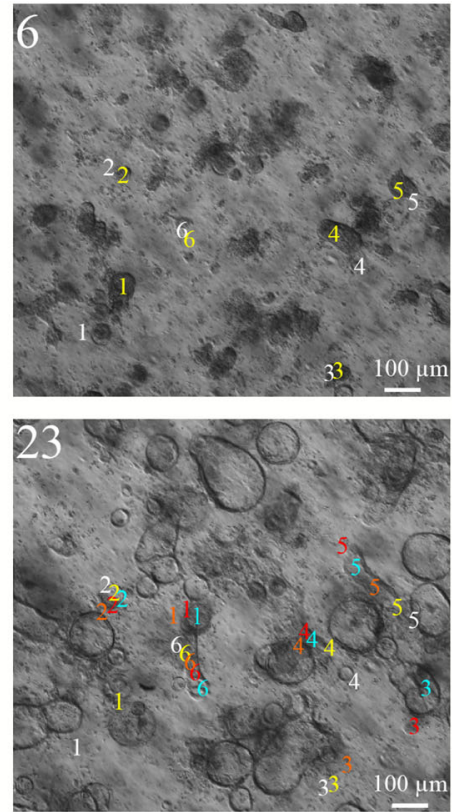
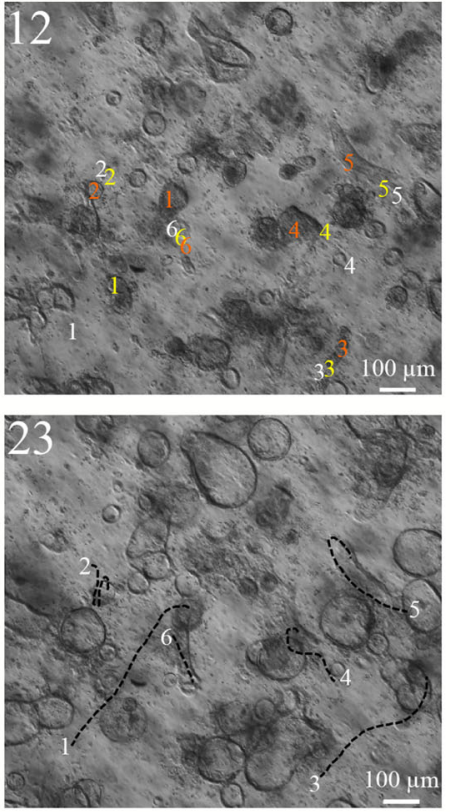

b
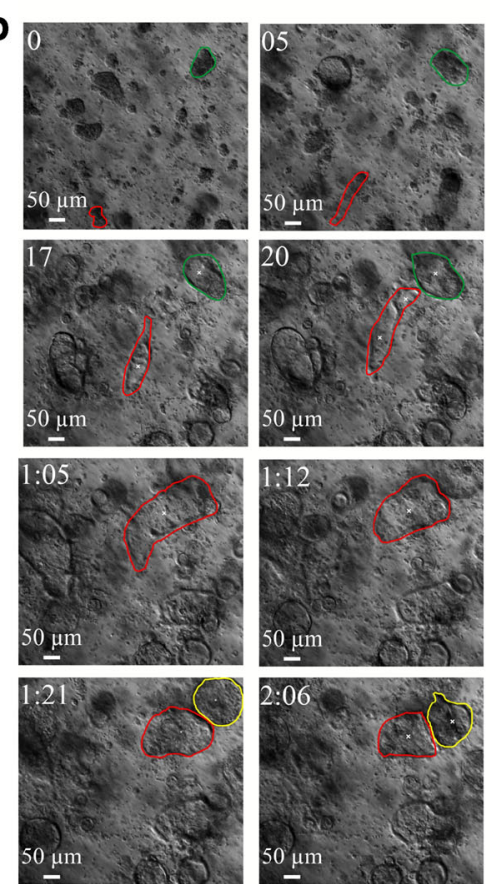
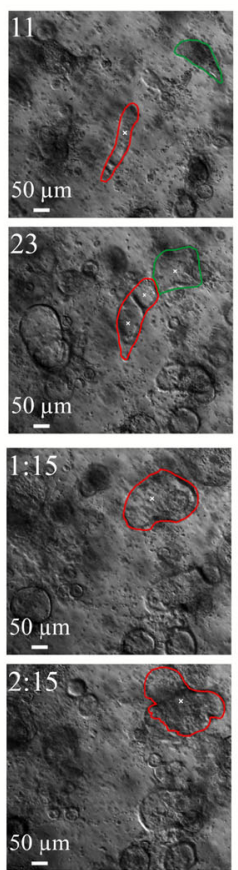

C
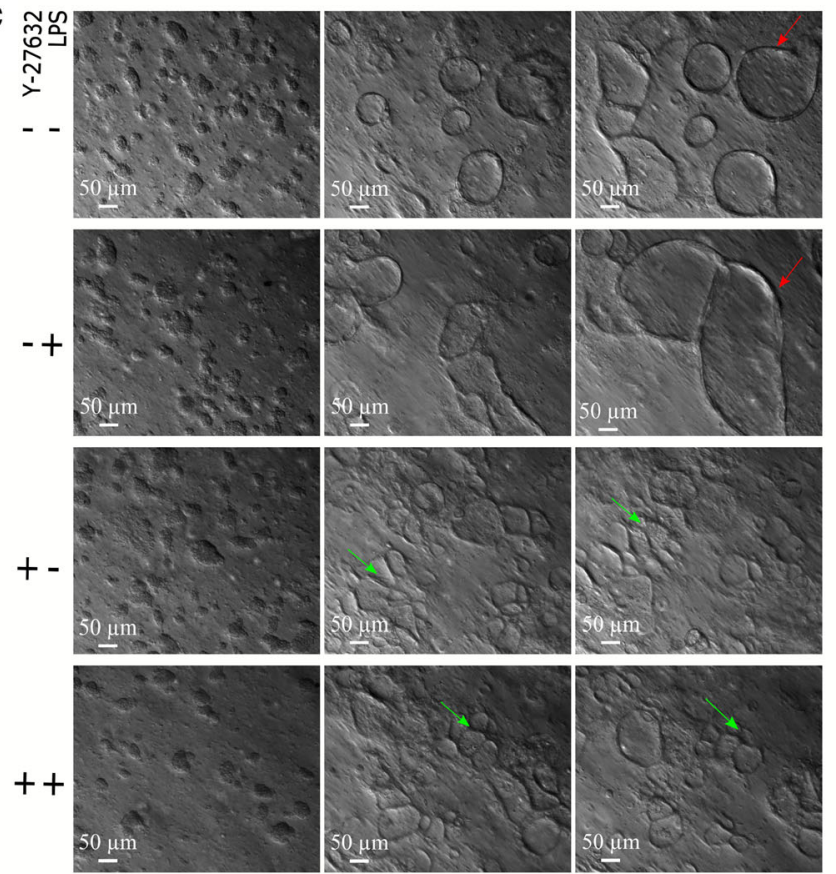

0

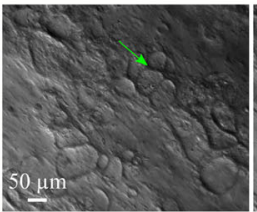

$1 d$
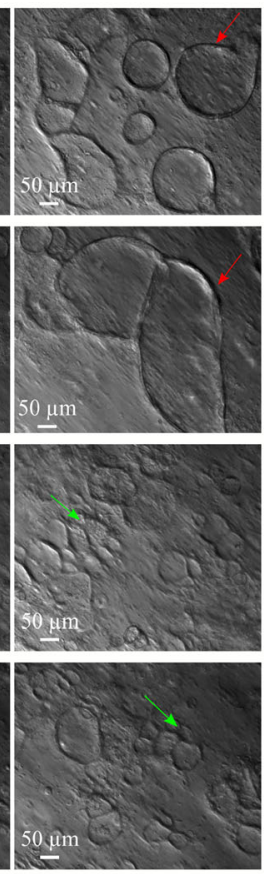

$2 d$ d

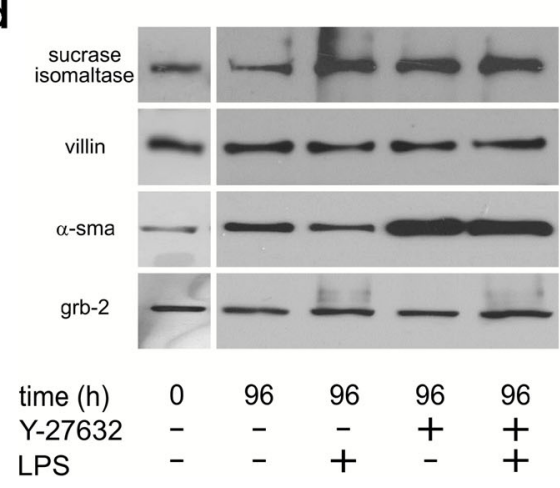

e

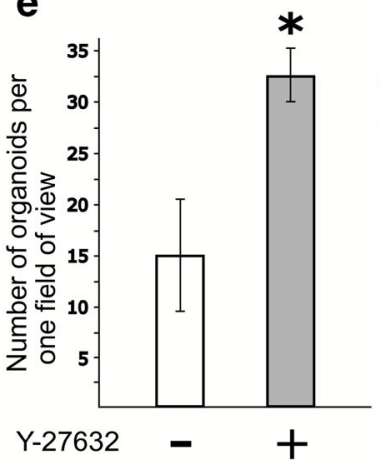

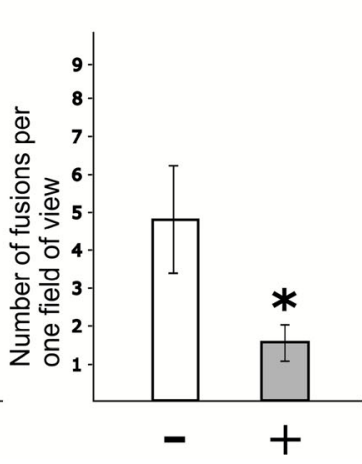


Fig. 1 The dynamic of organoids growth - the migration and fusion events in various culture conditions. The formation of organoids was recorded under an inverted microscope equipped with an incubation chamber, by collecting one image every half an hour in the first 3 days of culture. a The location of organoids moving through the Matrigel parallel to the insert surface was marked by numbers (1-6); the position of given organoid center at time 0 is shown with a white number; and at $6 \mathrm{~h}$-yellow, $12 \mathrm{~h}$-orange, $18 \mathrm{~h}$-red, and $23 \mathrm{~h}$-blue. The black dashed lines on the photograph in the lower right corner of the panel represent the distances covered by moving organoids in the first whole day of culture (see also Suppl. video 1). b The organoids moving towards one another and the fusion events between them were also recorded. The boundaries of three individual organoids that fused into one structure were contoured in red, green, and yellow. The lumen formation is marked by a white cross (see also Suppl. video 2). c The presence of ultrapure lipopolysaccharides from Escherichia coli 0111:B4 (LPS, $1 \mu \mathrm{g} / \mathrm{ml})$ in the medium caused the formation of larger organoids on days 2 and 3 from seeding, as compared to the organoids cultured without such stimulation (C, red arrows). The addition of Y-27632 $(10 \mu \mathrm{M})$ resulted in the formation of more organoids but of smaller size, regardless of the LPS presence (C, green arrows, see also Suppl. video 4). $\mathbf{d}$ The epithelial lining obtained by incubation of the intestines of 19-day-old chicken embryos in PBS contacting EGTA and glucose for $2 \mathrm{~h}$ was used for total protein isolation and subsequent immunoblotting (time 0). The tissue fragments isolated in the same way were used to start the organoid cultures. Organoids were cultured for 3 days without LPS and Y-27632 or with LPS $(1 \mu \mathrm{g} / \mathrm{ml})$ or with Y-27632 $(10 \mu \mathrm{M})$ or both. Upon completion of the time-lapse video recording, the media were exchanged and cultures were transferred to the incubator. After $96 \mathrm{~h}$ of culture, the total cellular proteins were isolated and the presence of enterocyte markers (sucrase-isomaltase and villin), myofibroblasts marker ( $\alpha$-smooth muscle actin $-\alpha$-sma), and loading control (growth factor receptor-bound protein 2-grb2) was detected by immunoblotting. The protein samples from organoid cultures treated with Y-27632 inhibitor contain much more $\alpha$-sma. e The projection area of organoids and number of organoids in one field of view were calculated from digitized images of cultures kept with the absence (open bars) or presence (closed bars) of ROCK inhibitor, which were taken at $72 \mathrm{~h}$ from seeding. All fusion events occurring in the first $48 \mathrm{~h}$ were calculated by a time-lapse video analysis (the mean of five independent measurements is presented). An ANOVA test was performed to confirm the significance of the difference between organoids cultured with and without Y-27632: $p$ value below 0.05 was considered significant and marked by asterisks (see also Suppl. video 4)

also promoted by the environment with lower stiffness (data not shown).

It is also worth noticing that - in contrast to mammalian systems - chicken embryo intestinal organoid culture comprises myofibroblasts. It seems that fibroblasts are important in the collective movement of tumor cells in 3D, enhancing their invasiveness. For example, it was shown that migration of squamous cell carcinoma cell clusters into the surrounding matrix is led by fibroblasts (Gaggioli et al. 2007) and collective cellular movement of ameloblastoma cells was enhanced in vitro by the presence of stromal fibroblasts (Fuchigami et al. 2017). It is possible that in the case of chicken intestinal organoids, the presence of myofibroblasts boosts effective organoid migration. As far as the cooperation of various cell types inside organoids is concerned, one can take into account the reorganization of adherens junctions and the force of transmission through them.
It was demonstrated that remodeling of adherens junctions controls cell-cell cooperation during collective cell migration of MDCKII monolayers by the $\alpha$-catenin-related mechanism (Matsuzawa et al. 2018) and some studies point to the specific role of various cadherins, e.g., E-cadherin and P-cadherin, in collective cell movement in 3D (Plutoni et al. 2016). Similarly, atypical Fat2 cadherin of Drosophila melanogaster is supposed to regulate collective cell movement during tissue rotation (Squarr et al. 2016). Although such detailed analysis was beyond the scope of the current communication, it would be interesting in the future to investigate the reorganization of adherens junctions and the role of their constituent proteins in moving intestinal organoids.

The inhibition of Rho-associated coiled coil-containing protein kinases (ROCKs) activity was shown to prevent some types of individual cell migration, as of Amoeba proteus (Kłopocka and Redowicz 2004) or breast cancer cells (Guerra et al. 2017) and also some types of collective cell movement (Mikami et al. 2015). However, it was also reported that ROCK inhibitors enhance other migratory activities, such as the movement of various cell types: endothelial cells from spheroids (Breyer et al. 2012), human proximal tubular epithelial cells, and epithelial cells of intestinal origin (Hopkins et al. 2007). The ROCK inhibitor Y27632 is also widely used as a stimulant of stem cell survival, which increases the efficiency of the formation of intestinal organoids (Han et al. 2017).

The ROCK activity is generally considered profibrotic, promoting the transition of epithelial-mesenchymal and fibroblasts-myofibroblasts (Ji et al. 2014). On the other hand, some authors concluded that the Y-27632 inhibitor augments myofibroblast proliferation and migration in culture (Piltti et al. 2015). It was also demonstrated that ROCK inhibitors primed human-induced pluripotent stem cells to selectively differentiate towards mesendodermal lineage (Maldonado et al. 2016), which is in line with our observation of the increased proportion of myofibroblasts in 4-day-old organoid cultures treated with the ROCK inhibitor. Though it is not clear whether the abundance of myofibroblasts plays any role in counteracting fusion events, one can speculate that their localization in close proximity to the epithelial walls of organoids may preclude the contacts between the sheets of epithelial cells of the congested spheres.

Two recently published studies dealt with dynamic behavior of gastrointestinal organoids: one demonstrated that human gastric epithelial spheroids could rupture, rotate, and fuse (Sebrell et al. 2018) and the other showed some contractile activity of neonatal murine intestinal organoids (containing mesenchymal cells) cultured in an air-liquid interface (di Marco et al. 2014). So far, the migration of enteroids or organoids through the Matrigel matrix has not been studied and we are convinced that the mechanism of this sort of collective cell movement deserves future attention. Obviously, 
further systematic research is required to find out if the migratory properties of organoids described in this report are characteristic for fetal tissue only, or if the elastic properties of the matrix (e.g., Matrigel concentration) can influence the shape changes and movement of organoids.

When organoids are being used as model systems mimicking the intestinal tissue (so-called mini guts models) to test the influence of various compounds or microorganisms on mucosal physiology, the comparison of such culture parameters as the diameter and number of organoids is routinely performed. In this sort of experiment, fusion events and possible migratory activity of organoids are generally overlooked, especially if time-lapse video recording is not performed. This might lead the authors of such studies to conclude that the larger the organoid diameter, the more stem cells proliferate in the organoid wall, but that might not always be the only explanation. When organoids are microinjected with harmful pathogens (as, e.g., in Dutta and Clevers 2017), commensal bacteria (as, e.g., Karve et al. 2017), or with beneficial or toxic food components, to mimic their presence in the intestinal lumen, the fusion between organoids might also be a cause of misinterpretation of the experimental results. The same problems could occur when inside-out and outside-in transports between a lumen and an extracellular space or the process of lumen acidification are studied. Therefore, we conclude that migration and fusion events should not be neglected during the design of experimental settings, when the impact of various factors on the morphology of organoids is analyzed.

Acknowledgements The authors would like to thank Dr. Alan G. Crosby for the language correction of the manuscript.

Funding information The financial support for this study was provided by the Polish National Science Center (grant no. 2013/09/B/NZ9/00285 to M. Pierzchalska).

\section{Compliance with ethical standards}

Conflict of interest The authors declare that they have no conflict of interest.

Open Access This article is distributed under the terms of the Creative Commons Attribution 4.0 International License (http:// creativecommons.org/licenses/by/4.0/), which permits unrestricted use, distribution, and reproduction in any medium, provided you give appropriate credit to the original author(s) and the source, provide a link to the Creative Commons license, and indicate if changes were made.

\section{References}

Beyaz S, Mana MD, Roper J, Kedrin D, Saadatpour A, Hong SJ, BauerRowe KE, Xifaras ME, Akkad A, Arias E, Pinello L, Katz Y, Shinagare S, Abu-Remaileh M, Mihaylova MM, Lamming DW, Dogum R, Guo G, Bell GW, Selig M, Nielsen GP, Gupta N, Ferrone CR, Deshpande V, Yuan GC, Orkin SH, Sabatini DM,
Yilmaz ÖH (2016) High-fat diet enhances stemness and tumorigenicity of intestinal progenitors. Nature 531:53-58. https://oi.org/ 10.1038/nature17173

Breyer J, Samarin J, Rehm M, Lautscham L, Fabry B, Goppelt-Struebe M (2012) Inhibition of Rho kinases increases directional motility of microvascular endothelial cells. Biochem Pharmacol 83:616-626. https://doi.org/10.1016/j.bcp.2011.12.012

di Marco R, Su J, Yan KS et al (2014) Engineering of three-dimensional microenvironments to promote contractile behavior in primary intestinal organoids. Integr Biol 6:127-142. https://doi.org/10.1039/ c3ib40188j

Dutta D, Clevers H (2017) Organoid culture systems to study host-pathogen interactions. Curr Opin Immunol 48:15-22. https://doi.org/10. 1016/j.coi.2017.07.012

Fuchigami T, Koyama H, Kishida M, Nishizawa Y, Iijima M, Kibe T, Ueda M, Kiyono T, Maniwa Y, Nakamura N, Kishida S (2017) Fibroblasts promote the collective invasion of ameloblastoma tumor cells in a 3D coculture model. FEBS Open Bio 7:2000-2007. https://doi.org/10.1016/j.contraception.2015.12.017.Women

Gaggioli C, Hooper S, Hidalgo-Carcedo C, Grosse R, Marshall JF, Harrington K, Sahai E (2007) Fibroblast-led collective invasion of carcinoma cells with differing roles for RhoGTPases in leading and following cells. Nat Cell Biol 9:1392-1400. https://doi.org/10.1038/ ncb1658

Gjorevski N, Piotrowski AS, Varner VD, Nelson CM (2015) Dynamic tensile forces drive collective cell migration through threedimensional extracellular matrices. Sci Rep 5:11458. https://doi. org/10.1038/srep 11458

Guerra FS, Oliveira RG, De Fraga CAM et al (2017) ROCK inhibition with Fasudil induces beta-catenin nuclear translocation and inhibits cell migration of MDA-MB 231 human breast cancer cells. Sci Rep 7:1-8. https://doi.org/10.1038/s41598-017-14216-z

Han SH, Shim S, Kim MJ, Shin HY, Jang WS, Lee SJ, Jin YW, Lee SS, Lee SB, Park S (2017) Long-term culture-induced phenotypic difference and efficient cryopreservation of small intestinal organoids by treatment timing of rho kinase inhibitor. World J Gastroenterol 23:964-975. https://doi.org/10.3748/wjg.v23.i6.964

Hiraiwa T, Kuranaga E, Shibata T (2017) Wave propagation of junctional remodeling in collective cell movement of epithelial tissue: numerical simulation study. Front Cell Dev Biol 5:1-15. https://doi.org/10. 3389/fcell.2017.00066

Hopkins AM, Pineda AA, Winfree LM et al (2007) Organized migration of epithelial cells requires control of adhesion and protrusion through Rho kinase effectors. Am J Physiol Gastrointest Liver Physiol 292:G806-G817. https://doi.org/10.1152/ajpgi.00333.2006

Jabaji Z, Brinkley GJ, Khalil HA, Sears CM, Lei NY, Lewis M, Stelzner M, Martín MG, Dunn JCY (2014) Type I collagen as an extracellular matrix for the in vitro growth of human small intestinal epithelium. PLoS One 9:1-9. https://doi.org/10.1371/journal.pone.0107814

Ji H, Tang H, Lin H et al (2014) Rho/Rock cross-talks with transforming growth factor- $\beta /$ Smad pathway participates in lung fibroblastmyofibroblast differentiation. Biomed Reports 2:787-792. https:// doi.org/10.3892/br.2014.323

Karve SS, Pradhan S, Ward DV, Weiss AA (2017) Intestinal organoids model human responses to infection by commensal and Shiga toxin producing Escherichia coli. PLoS One 12:1-20. https://doi.org/10. 1371/journal.pone.0178966

Kłopocka W, Redowicz MJ (2004) Rho/Rho-dependent kinase affects locomotion and actin-myosin II activity of Amoeba proteus. Protoplasma 224:113-121. https://doi.org/10.1007/s00709-0040056-4

Maldonado M, Luu RJ, Ramos MEP, Nam J (2016) ROCK inhibitor primes human induced pluripotent stem cells to selectively differentiate towards mesendodermal lineage via epithelial-mesenchymal transition-like modulation. Stem Cell Res 17:222-227. https://doi. org/10.1016/j.scr.2016.07.009 
Matsumoto T, Mochizuki W, Nibe Y, Akiyama S, Matsumoto Y, Nozaki K, Fukuda M, Hayashi A, Mizutani T, Oshima S, Watanabe M, Nakamura T (2016) Retinol promotes in vitro growth of proximal colon organoids through a retinoic acid-independent mechanism. PLoS One 11:1-15. https://doi.org/10.1371/journal.pone.0162049

Matsuzawa K, Himoto T, Mochizuki Y, Ikenouchi J (2018) a-catenin controls the anisotropy of force distribution at cell-cell junctions during collective cell migration. Cell Rep 23:3447-3456. https:// doi.org/10.1016/j.celrep.2018.05.070

Mikami T, Yoshida K, Sawada H, Esaki M, Yasumura K, Ono M (2015) Inhibition of Rho-associated kinases disturbs the collective cell migration of stratified TE-10 cells. Biol Res 48:1-15. https://doi.org/ 10.1186/s40659-015-0039-2

Ootani A, Li X, Sangiorgi E, Ho QT, Ueno H, Toda S, Sugihara H, Fujimoto K, Weissman IL, Capecchi MR, Kuo CJ (2009) Sustained in vitro intestinal epithelial culture within a Wntdependent stem cell niche. Nat Med 15:701-706. https://doi.org/ $10.1038 / \mathrm{nm} .1951$

Panek M, Grabacka M, Pierzchalska M (2018) The formation of intestinal organoids in a hanging drop culture. Cytotechnology 70:10851095. https://doi.org/10.1007/s10616-018-0194-8

Pegoraro AF, Fredberg JJ, Park JA (2016) Problems in biology with many scales of length: cell-cell adhesion and cell jamming in collective cellular migration. Exp Cell Res 343:54-59. https://doi.org/10.1016/ j.yexcr.2015.10.036

Pierzchalska M, Grabacka M, Michalik M, Zyla K, Pierzchalski P (2012) Prostaglandin E2 supports growth of chicken embryo intestinal organoids in Matrigel matrix. Biotechniques 52:307-315. https:// doi.org/10.2144/0000113851

Pierzchalska M, Panek M, Czyrnek M, Grabacka M (2016) The threedimensional culture of epithelial organoids derived from embryonic chicken intestine. Methods Mol Biol. https://doi.org/10.1007/7651 2016_15

Pierzchalska M, Panek M, Czyrnek M, Gielicz A, Mickowska B, Grabacka M (2017) Probiotic Lactobacillus acidophilus bacteria or synthetic TLR2 agonist boost the growth of chicken embryo intestinal organoids in cultures comprising epithelial cells and myofibroblasts. Comp Immunol Microbiol Infect Dis 53:7-18. https://doi.org/10.1016/j.cimid.2017.06.002

Piltti J, Varjosalo M, Qu C, Häyrinen J, Lammi MJ (2015) Rho-kinase inhibitor Y-27632 increases cellular proliferation and migration in human foreskin fibroblast cells. Proteomics 15:2953-2965. https:// doi.org/10.1002/pmic.201400417

Plutoni C, Bazellières E, Gauthier-Rouvière C (2016) P-cadherinmediated Rho GTPase regulation during collective cell migration.
Small GTPases 7:156-163. https://doi.org/10.1080/21541248.2016. 1173772

Rørth P (2012) Fellow travellers: emergent properties of collective cell migration. EMBO Rep 13:984-991. https://doi.org/10.1038/embor. 2012.149

Sachs N, Tsukamoto Y, Kujala P, Peters PJ, Clevers H (2017) Intestinal epithelial organoids fuse to form self-organizing tubes in floating collagen gels. Development 144:1107-1112. https://doi.org/10. $1242 /$ dev. 143933

Sato T, Vries RG, Snippert HJ, van de Wetering M, Barker N, Stange DE, van Es JH, Abo A, Kujala P, Peters PJ, Clevers H (2009) Single Lgr5 stem cells build crypt-villus structures in vitro without a mesenchymal niche. Nature 459:262-265. https://doi.org/10.1038/ nature 07935

Sato K, Hiraiwa T, Maekawa E, Isomura A, Shibata T, Kuranaga E (2015) Left-right asymmetric cell intercalation drives directional collective cell movement in epithelial morphogenesis. Nat Commun 6:10074. https://doi.org/10.1038/ncomms 10074

Scarpa E, Mayor R (2016) Collective cell migration in development. J Cell Biol 212:143-155. https://doi.org/10.1083/jcb.201508047

Sebrell TA, Sidar B, Bruns R, Wilkinson RA, Wiedenheft B, Taylor PJ, Perrino BA, Samuelson LC, Wilking JN, Bimczok D (2018) Live imaging analysis of human gastric epithelial spheroids reveals spontaneous rupture, rotation and fusion events. Cell Tissue Res 371: 293-307. https://doi.org/10.1007/s00441-017-2726-5

Sharma Y, Vargas DA, Pegoraro AF, Lepzelter D, Weitz DA, Zaman MH (2015) Collective motion of mammalian cell cohorts in 3D. Integr Biol (United Kingdom) 7:1526-1533. https://doi.org/10.1039/ c5ib00208g

Simian M, Bissell MJ (2017) Organoids: a historical perspective of thinking in three dimensions. J Cell Biol 216:30-40. https://doi.org/10. 1083/jcb.201610056

Squarr AJ, Brinkmann K, Chen B, Steinbacher T, Ebnet K, Rosen MK, Bogdan S (2016) Fat2 acts through the WAVE regulatory complex to drive collective cell migration during tissue rotation. J Cell Biol 212:591-603. https://doi.org/10.1083/jcb.201508081

Viktorinová I, Henry I, Tomancak P (2017) Epithelial rotation is preceded by planar symmetry breaking of actomyosin and protects epithelial tissue from cell deformations. PLoS Genet 13:e1007107. https://doi. org/10.1371/journal.pgen.1007107

Zachos NC, Kovbasnjuk O, Foulke-Abel J, in J, Blutt SE, de Jonge HR, Estes MK, Donowitz M (2016) Human enteroids/colonoids and intestinal organoids functionally recapitulate normal intestinal physiology and pathophysiology. J Biol Chem 291:3759-3766. https:// doi.org/10.1074/jbc.R114.635995 